\title{
Effect of Electrical Stimulation of Abdominal and Back Muscles on Balance in Children with Spastic Diplegia
}

\author{
NOUR EL-HODA M. AHMED, B.Sc.*; EMAM H. EL-NEGAMY, Ph.D.*; AMINA H. SALEM, M.D.** and \\ RAMI M. GHARIB, Ph.D.* \\ The Department of Physical Therapy for Growth \& Development Disorders in Children \& its Surgery, \\ Faculty of Physical Therapy* and The Department of Pediatric Neurology, Faculty of Medicine**, Cairo University
}

\begin{abstract}
Background: Spastic diplegia is one of the most common clinical subtypes of cerebral palsy regardless of birth weight and gestation. It is used when there is motor impairment in the upper extremities as well as the lower extremities, although it is milder in the upper extremities than the lower one. Children with spastic diplegia may exhibit clumsiness and frequent falls during regular motor activities or may not be able to maintain standing position independently.
\end{abstract}

Aim of the Study: The purpose of this study was to investigate the effect of neuromuscular electrical stimulation of abdominal and back muscles on balance in spastic diplegic children.

Material and Methods: Thirty children with spastic diplegic $\mathrm{CP}$ of both sexes were selected, ranging in age from 4 to 8 years. They were classified randomly into two groups of equal number (A \& B). Evaluation of children balance was performed before and after 6 weeks of treatment using Biodex stability system. Group (A) received traditional physical therapy program based on neurodevelopmental approach used for rehabilitation of such patients and Group (B) received the same traditional physical therapy program applied on Group (A) in addition to $30 \mathrm{~min}$ neuromuscular electrical stimulation of abdominal and back muscles.

Results: No significant difference in Overall Dynamic Stability Index, Antero/Posterior Stability Index and, Medio/ Lateral Stability Index (ODSI, APSI, and MLSI) was recorded between the two groups before treatment, significant improvement was recorded in ODSI, APSI, and MLSI in each group after treatment. Significant differences in ODSI, APSI, and MLSI were recorded between the two groups after treatment in favor of Group (B).

Conclusion: From the obtained results of this study, supported by the relevant literature it can be concluded that neuromuscular electrical stimulation of abdominal and back muscles can be added to the physical therapy program to improve the balance in spastic diplegic children.

Correspondence to: Dr. Nour El-Hoda M. Ahmed, The Department of Physical Therapy for Growth \& Development Disorders in Children \& its Surgery, Faculty of Physical Therapy, Cairo University
Key Words: Balance - Spastic diplegic cerebral palsy - Neuromuscular electrical stimulation.

\section{Introduction}

CEREBRAL Palsy (CP) is the most common cause of physical disability in childhood, with an estimated incidence of 2.11 per 1000 live births [1]

Cerebral palsy is an umbrella term covering a group of non-progressive, but often changing, motor impairment syndromes secondary to lesion or anomalies of the brain arising in the early stage of its development [2].

Spastic diplegia is the common term applied to a variation of spastic quadriparesis in which the lower limbs are more affected than upper limbs. It accounts for approximately $50 \%$ of total CP population [3]

The children with diplegic CP may not have trunk control because they have spasticity and weakness in their trunk muscles. Coordinated activation of extensors and flexors of trunk favors for well-balanced sitting posture [4].

Neuromuscular Electrical Stimulation (NMES) is a promising therapy for strengthening muscles in patients with CP [5]. Neuromuscular Electrical Stimulation (NMES) is the application of an electrical current of sufficient intensity to elicit muscle contraction. Two strengthening mechanisms are proposed for the therapeutic effects of NMES: (1) The overload principle, resulting in greater muscle strength by increasing the cross-sectional area of the muscle; and (2) Selective recruitment of type II fibers (fast-twitch, large diameter fibers), causing improved synaptic efficiency of the muscle [6] . 
For individuals with $\mathrm{CP}$, NMES has been recommended for the stimulation of muscles in the limbs and trunk and can lead to significant improvements in muscle strength and range of motion as well as the modulation of excessive muscle tone and enhanced coordination [7]

NMES has been previously studied in CP children and found to be effective on trunk control. It has also been reported that it is more effective when NMES is combined with other conventional rehabilitation methods [8].

\section{Subjects and Methods}

This study was conducted during period from November 2016 to June 2017 in the outpatient clinic at the Faculty of Physical Therapy, Cairo University to investigate the effect of neuromuscular electrical stimulation of abdominal and back muscles on the balance in spastic diplegic children.

Thirty spastic diplegic C.P children of both sexes have participated in this study. Their ages ranged from 4 to 8 years. All subjects were recruited from out-patient clinic, Faculty of Physical Therapy, Cairo University. Children were assigned randomly to two groups of equal number 15 patients each:

Group A: Received traditional physical therapy program.

Group B: Received traditional physical therapy program as in Group A in addition to 30 minutes neuromuscular electrical stimulation of abdominal and back muscles.

Ethical consideration; the purpose, nature and potential risks of the study were explained to all patients. All patients and their families signed a consent form prior to participation in the study. All children were required to meet a strict set of inclusion criteria: Children height was one meter or more to be able to see the screen, able to understand and follow simple orders, not using any orthotic device or support and they had balance problems collected from child history of repeated and frequent falling especially when increasing speed or walking on uneven surface as chief complain of parents.

\section{Exclusion criteria:}

Exclusion criteria were as follows: Children with history of epileptic fits, receiving anti spastic drugs, have visual or auditory defects; have fixed deformities in the lower limbs.

\section{Evaluation procedures:}

Assessment procedure was performed for all patients in the two groups before and after six weeks of treatment.

\section{- Modified ashworth scale:}

Used to quantify the degree of spasticity for the selection of the patients (grade 1 and 2 were selected).

\section{- Standard weight and height scale:}

Weight in kilogram $(\mathrm{kg})$ and height in centimeter $(\mathrm{cm})$ were recorded for each subject before starting the evaluation.

\section{- Biodex stability system:}

The Biodex stability system (Biodex medical system, Shirley, New York) is a unique dynamic postural control assessment and training system. The Biodex stability system consists of a movable balance platform which can be set at variable degrees of instability. This system is interfaced with computer software monitored through the control panel screen and is supplied with Cannon Bubble Jet printer to print the test results [9]

This test was performed to test the subject's ability to control the platform angle of tilt.

At the end of each test, a printout report was obtained. This report included information as regard to:

- Overall dynamic stability index: Represents the subject's ability to control their balance in all directions.

- Anterior/posterior stability index: Represents the subject's ability to control their balance in front to back directions.

- Medial/lateral stability index: Represents the subject's ability to control their balance from side to side. High values represent that subjects have difficulty.

\section{Treatment procedures:}

\section{Neuromuscular electrical stimulation:}

The neuromuscular electrical stimulator used was the phyaction 787 , manufactured in Netherlands by Unify BV, the NMES delivered over the abdominal and back muscles at the following parameters: Intensity was $25-30 \mathrm{~mA}$, pulse width $250 \mathrm{tsec}$, frequency $35 \mathrm{~Hz}$ with $10 \mathrm{sec}$ on and $12 \mathrm{sec}$ off interval for 30 minutes per session for 3 days a week for 6 successive weeks. The intensity was adjusted to the tolerance of the child, which was kept at the intensity of muscle contraction felt and seen. Neuromuscular electrical stimulation was 
delivered over the abdominal and back muscles simultaneously via eight surface electrodes, four applied on rectus abdominus of both sides and four applied on erector spinae muscles of both sides.

\section{Physical therapy tools:}

Mats, balls, rolls, wedges of different size and balance boards were used to conduct the regular physical therapy program.

\section{Traditional physical therapy program:}

The two groups received the physical therapy treatment program for three times per week, every other day for 6 successive weeks as follows:

1- Neurodevelopmental approach directed towards inhibiting abnormal muscle tone and abnormal postural reflexes and facilitation of normal movement patterns of postural control through reflex inhibiting positions using proximal and distal key points of control.

2- Approximation as proprioceptive training applied in a slow and rhythmic manner for upper limbs, lower limbs and trunk to modulate spasticity and stimulate the joint mechanoreceptors from semi reclined and quadruped positions.

3- Training for active trunk extension to improve postural control and balance.

4- Balance training from different positions, from quadruped position, kneeling, half kneeling and standing position on mat and tilting board.

5- Facilitation of righting and equilibrium reactions to improve postural mechanisms via variety of exercises applied on ball and balance board through tilting from different positions in forward, backward and sideways.

6- Facilitation of protective reactions by applying fast and large amplitude of the stimulus to train saving reactions from sitting on roll and from standing position by pushing the child to enhance the child to take protective steps either forward, backward or sideways to regain balance.

7- Facilitation of standing from supine and prone and facilitation of single limb support while standing facing the stand bar by the therapist and by using blocks.

8- Hand weight bearing exercises and approximation to improve the hand function. Facilitation of reaching, grasping and release according to the child abilities.

9- Stretching exercises to maintain the length and the elastic properties of the muscles which are liable for shortening especially Achilles tendon, hamstrings and hip flexors while in the upper limbs the shoulder internal rotators, elbow and wrist flexors, pronators and ulnar deviators.

10- Gait training activities also were applied as important elements for balance training including:

- Sideway and forward walking between the parallel bars in front of a large mirror and walking training using stepper.

- Walking in open environment by placing obstacles across walking tract as rolls of different diameter and wedges of different heights.

- Training of walking on different floor surfaces (Spongy and hard surfaces) on mat, on the floor and on the carpets.

\section{Statistical analysis:}

To compare improvement after the intervention in each group, the independent $t$-test was used to compare demographic and clinical characteristics of the patients in both groups, 2 X 2 mixed design MANOVA was used to compare the tested variables of interest at different tested groups and measuring periods. A significance level of P-value less than 0.05 was considered.

Statistical analysis was conducted using SPSS for windows. The current test involved two independent variables. The first one was the (tested group); between subject factor which had two levels (Group A receiving the regular physical therapy program for such cases and Group B receiving the regular physical therapy program in addition to neuromuscular electrical stimulation of abdominal and back muscles). The second one was the (measuring periods); within subject factor which had two levels (pre, post). In addition, this test involved four tested dependent variables (over all stability index, AP stability index, ML stability index).

\section{Results}

A total of 30 spastic diplegic children were divided into two groups: Group (A) consisted of 15 children with mean age values of $6.4 \pm 1.71$ years. Group (B) consisted of 15 children with mean age values of $6.4 \pm 1.64$ years. As indicated by the independent $t$-test, there were no significant differences $(p>0.05)$ in the mean values of age between both tested groups (Table 1). The sex distribution of Group A revealed that there were 5 females with reported percentage of $33.3 \%$ and 10 males with reported percentage of $66.7 \%$. The sex distribution of Group B revealed that there 
were 5 females with reported percentage of $33.3 \%$ and 10 males with reported percentage of $66.7 \%$ with no significant differences between both groups in sex distribution $(p>0.05)$ as shown in (Table 1).

Statistical analysis using 2 X 2 mixed design MANOVA was carried out to examine the differences between and within the two groups before and after the treatment. Results showed that before treatment, there was no significant difference between the two groups in all parameters (over all stability index, AP stability index, ML stability index), while significant improvement in the measuring variables of both the control and study groups was recorded when comparing the pre and post treatment mean values of each group. However, significant difference was recorded between the two groups when comparing the post treatment mean values of the two groups in favor to Group (B).

\section{Overall stability index:}

As presented in (Table 2) within group's comparison revealed that there was significant reduction of overall stability index at post treatment in compare to pretreatment in both groups while between groups the multiple pairwise comparison tests revealed that there was no significant difference of mean values of the "pre" test significant difference of the mean values of the "post" test between both groups with $\left(p=0.009^{*}\right)$ and this significant reduction in favor to Group B.

\section{AP stability index:}

As presented in (Table 3) within group's comparison revealed that there was significant reduction of AP stability index at post treatment in compare to pretreatment in both groups while between groups the multiple pairwise comparison tests revealed that there was no significant difference of mean values of the "pre" test significant difference of the mean values of the "post" test between both groups with $\left(p=0.009^{*}\right)$ and this significant reduction in favor to Group B.

\section{ML stability index:}

As presented in (Table 4) within group's comparison revealed that there was significant reduction of ML stability index at post treatment in compare to pretreatment in both groups while between groups the multiple pairwise comparison tests revealed that there was no significant difference of mean values of the "pre" test significant difference of the mean values of the "post" test between both groups with $\left(p=0.009^{*}\right)$ and this significant reduction in favor to Group B.
Table (1): Demographic and clinical characteristics of the patients in the two groups.

\begin{tabular}{lcccccc}
\hline & \multirow{2}{*}{ Items } & Group A & Group B & \multicolumn{3}{c}{ Comparison } \\
\cline { 4 - 6 } & Mean \pm SD & Mean \pm SD & $t$-value & $p$-value & $\mathrm{S}$ \\
\hline Age (yrs) & $6.4 \pm 1.71$ & $6.4 \pm 1.64$ & 0.642 & 0.525 & $\mathrm{NS}$ \\
\hline & \multicolumn{5}{c}{ Sex distribution N (\%) } \\
\cline { 3 - 6 } & Group A & Group B & $\chi^{2}$ & $p$-value & $\mathrm{NS}$ \\
\hline Female & $5(33.3 \%)$ & $5(33.3 \%)$ & 0.000 & 1.00 & $\mathrm{NS}$ \\
Male & $10(66.7 \%)$ & $10(66.7 \%)$ & & & \\
\hline
\end{tabular}

*SD : Standard Deviation

$p \quad:$ Probability.

$S$ : Significance.

NS : Non-Significant.

Table (2): Mean \pm SD and $p$-values of overall stability index pre and post test in the two groups.

\begin{tabular}{llllll}
\hline $\begin{array}{l}\text { Overall } \\
\text { stability } \\
\text { index }\end{array}$ & $\begin{array}{c}\text { Pre test } \\
\text { Mean } \pm \text { SD }\end{array}$ & $\begin{array}{c}\text { Post test } \\
\text { Mean } \pm \text { SD }\end{array}$ & MD & $\begin{array}{c}\% \text { of } \\
\text { change }\end{array}$ & $\begin{array}{c}p \text { - } \\
\text { value }\end{array}$ \\
\hline Group A & $2.91 \pm 0.36$ & $2.45 \pm 0.39$ & 0.46 & $15.8 \downarrow$ & $0.0001^{*}$ \\
Group B & $2.9 \pm 0.38$ & $2.06 \pm 0.37$ & 0.84 & $28.9 \downarrow$ & $0.0001^{*}$ \\
MD & 0.01 & 0.39 & & & \\
$p$-value & 0.923 & $0.009^{*}$ & & & \\
\hline
\end{tabular}

* : Significant level is set at alpha level $<0.05$.

SD : : Standard Deviation.

MD : Mean Difference.

$p$-value : Probability value.

Table (3): Mean \pm SD and $p$-values of AP stability index pre and post test in the two groups.

\begin{tabular}{llllll}
\hline $\begin{array}{l}\text { AP } \\
\text { stability } \\
\text { index }\end{array}$ & $\begin{array}{c}\text { Pre test } \\
\text { Mean } \pm \text { SD }\end{array}$ & $\begin{array}{c}\text { Post test } \\
\text { Mean } \pm \text { SD }\end{array}$ & MD & $\begin{array}{c}\% \text { of } \\
\text { change }\end{array}$ & $\begin{array}{c}p \text { - } \\
\text { value }\end{array}$ \\
\hline Group A & $2.30 \pm 0.44$ & $1.95 \pm 0.41$ & 0.35 & $15.2 \downarrow$ & $0.0001^{*}$ \\
Group B & $2.22 \pm 0.45$ & $1.52 \pm 0.37$ & 0.7 & $31.5 \downarrow$ & $0.0001^{*}$ \\
MD & 0.08 & 0.43 & & & \\
$p$-value & 0.602 & $0.005^{*}$ & & & \\
\hline
\end{tabular}

$\begin{array}{ll}* & : \text { Significant level is set at alpha level }<0.05 . \\ \text { SD } & : \text { Standard Deviation. } \\ \text { MD } & : \text { Mean Difference. } \\ p \text {-value : Probability value. }\end{array}$

Table (4): Mean \pm SD and $p$-values of ML stability index pre and post test in the two groups.

\begin{tabular}{llllll}
\hline $\begin{array}{l}\text { ML } \\
\text { Stability } \\
\text { index }\end{array}$ & $\begin{array}{c}\text { Pre test } \\
\text { Mean } \pm \text { SD }\end{array}$ & $\begin{array}{c}\text { Post test } \\
\text { Mean } \pm \text { SD }\end{array}$ & MD & $\begin{array}{c}\% \text { of } \\
\text { change }\end{array}$ & $\begin{array}{c}p \text { - } \\
\text { value }\end{array}$ \\
\hline Group A & $2.29 \pm 0.68$ & $1.92 \pm 0.60$ & 0.37 & $16.15 \downarrow$ & $0.006^{*}$ \\
Group B & $2.28 \pm 0.71$ & $1.28 \pm 0.42$ & 1 & $43.8 \downarrow$ & $0.0001^{*}$ \\
MD & 0.01 & 0.64 & & & \\
$p$-value & 0.959 & $0.002^{*}$ & & & \\
\hline
\end{tabular}

$\begin{array}{ll}* & : \text { Significant level is set at alpha level }<0.05 . \\ \text { SD } & : \text { Standard Deviation. } \\ \text { MD } & \text { : Mean Difference. } \\ p \text {-value : Probability value. }\end{array}$




\section{Discussion}

The present study included spastic diplegic type of cerebral palsy that constitutes a major classification among spastic types. This finding was reported by Thorogood [10] who stated that spastic diplegia accounts about nearly one-third of all spastic cerebral palsied cases as a result of brain lesion.

Children with CP may show a delay in the acquisition of various motor skills such as gross and fine motor functions. They often lack adequate stability due to impaired postural control and abnormal muscle tone resulting in defective or improper gait pattern [11].

The present study was conducted to investigate the effect of neuromuscular electrical stimulation on abdominal and back muscles in the balance of spastic diplegic children in addition to regular physical therapy program for such cases.

All patients were assessed before and after the treatment program by using the Biodex stability system to measure "overall stability index, anteroposterior stability index and mediolateral stability index" this comes in agreement with Finn et al., [12], who reported that Biodex stability system is becoming more widely available as means of accurately measuring balance as provides valid, reliable and repeatable objective measures of patient's ability to balance on stable and unstable surfaces and documents neuromuscular control in safe environments. During static and dynamic stability exercise and testing, the Balance System provides visual biofeedback of a patient's ability to control their Center of Gravity (COG).

The pre-treatment mean values of the dynamic balance test obtained from both groups regarding the measuring variables revealed non-significant statistical difference in the measuring variable. These findings clearly demonstrate the homogeneity between the two groups before starting the study reflecting the validity of the sample collection and random classification of children between the two groups. The pre-treatment results of the present study were consistent with those reported by Rose et al., [13], who concluded that high stability indices on the Biodex balance system indicate a lot of movement during the test (greater platform motion) and therefore less stability.

The post-treatment mean values of the study group revealed highly significant improvement and a significant difference in all variables in its favor which may be attributed to the effect of the neuromuscular electrical stimulation of abdominal and back muscle which provided better trunk control and stability which is essential for balance and functional activities.

This comes in agreement with Verheyden et al., [14], who reported that trunk stability is an essential core component of balance, and it is necessary for coordinated extremity use in daily functional activities and performance of higher level motor tasks.

The improvement in trunk stability may be attributed to the increased muscle strength of abdominal and back gained by neuromuscular electrical stimulation and this was in agreement with Cholewicki et al., [15], who stated that trunk stability requires appropriate muscle strength and neural control as well as adequate position sense to provide a stable foundation for movement.

Verheyden et al., [16], also have addressed the trunk as the central key point of the body, and the control of movement proceeds from proximal to distal body regions. Motor control literature suggests that if an improved level of proximal trunk control gains were attained, a better distal limb control might be anticipated during balance and functional mobility.

The significant improvement in balance showed in reduction of overall, anteroposterior and mediolateral stability index may be attributed to the effect of neuromuscular electrical stimulation on abdominal and back muscles in improving trunk control, this agrees with Karthikbabu et al., [17], who stated that the trunk is the central key point of the body; proximal trunk control is a prerequisite for distal limb movement control, balance, and functional activities.

The NMES has been reported to improve voluntary muscle activation and prevent muscular disuse atrophy in different populations including $\mathrm{CP}$. The most likely explanation is that NMES has the same effect as normal voluntary muscle contraction in causing a temporary increase in muscle metabolism and greater blood flow and facilitating more spinal motor neuron pools, stimulating blood flow to atrophied muscles to deliver growth factors and nutrients necessary to improve muscle structure and function [18]

\section{Conclusion:}

From the obtained results of this study, it can be concluded that neuromuscular electrical stimulation of abdominal and back muscles can be used to improve the balance of spastic diplegic children; 
so, it can be added as an additional therapeutic modality to assist in the rehabilitation program of such children.

\section{References}

1- OSKOUI M., COUTINHO F., DYKEMAN J., et al.: An update on the prevalence of cerebral palsy: A systematic review and meta-analysis. Dev. Med. Child. Neurol., 55: 509-19, 2013.

2- TOSO L., POGGI S., PARK H., et al.: Pediatric Neurology, 3 rd ed., Ediburgh, Chirchill Livingstone, pp. 260-8, 2005.

3- DAMIANO D., DARRAH J., PIPER M. and WATT M. Assessment of gross motor skills of at-risk infants: Predictive validity of the Alberta Infant Motor Scale. Dev. Med. Child Neurol., 2011.

4- KARABAY A., DOGAN M., ARSLAN G., et al.: Effects of functional electrical stimulation on trunk control in children with diplegic cerebral palsy, Disabil. Rehabil., 34 (11): 965e970, 2012.

5- WRIGHT P., DURHAM S., EWINS D. and SWAIN I.: Neuromuscular electrical stimulation for children with cerebralpalsy: A review. Arch. Dis. Child, 97: 364-71, 2011.

6- MERRILL D.: Review of electrical stimulation in cerebral palsy and recommendations for future directions, MacKeith Press Developmenta Medicine \& Child Neurology, 51 (Suppl. 4): 154-65, 2009.

7- WILLIAMS N. and FLUNN M.: A review of the efficacy of neuromuscular electrical stimulation in critically ill patients. Physiotherapy Theory Pract., 30: 611, 2014.

8- ARYA B., MOHAPATRA J., SUBRAMANYA K., et al.: Surface EMG analysis and changes in gait following electrical stimulation of quadriceps femoris and tibialis anterior in children with spastic cerebral palsy. Conf Proc. IEEE. Eng. Med. Biol. Soc., 5726-9, 2012.

9- CACHUPE W.J.C., SHIFFLETT B., KAHANOV L., et al.: Reliability of Biodex balance System measures. J. Measur. Physic. Educa. Exer. Scie., 5 (2): 97-108, 2001.

10- THOROGOOD C.: Cerebral Palsy: Introduction and Diagnosis (Part 1). J. Pediatric Health Care, 21 (3): 14652, 2012.

11- BAX M. and BROWEN J.: The spectrum of disorders known as cerebral palsy. Management of the motor disorders of children with cerebral palsy, 4 th ed, Mac Keith Press, Cambridge University Press, pp. 150-6, 2012.

12- FINN J., ALVAREX M., JETT R., et al.: Southern Connecticut State Univ. Stability Performance Assessment Among Subject of Disparate Balance Abilities, 2008.

13- ROSE J., WOLFF D., JONES V., et al.: Postural balance in children with cerebral palsy. Dev. Med. Child. Neurol., 44 (1): 58-63, 2005.

14- VERHEYDEN G., NIEUWBOER A., DEWIT L., et al.: Trunk performance after stroke: An eye catching predictor of functional outcome. J. Neurol. Neurosurg. Psychiatry, 78: 694-8, 2007.

15- CHOLEWICKI J., PANJABI M. and KHACHATRYAN A.: Stabilizing function of trunk flexor and extensor muscles around a neutral spine posture. Spine, 22: 220712, 2008.

16- VERHEYDEN G., VEREECK L., TRUIJEN S., et al.: Trunk performance after stroke and the relationship with balance, gait and functional ability. Clin. Rehabil., 20: 451-8, 2006.

17- KARTHIKBABU S., RAO B., MANIKANDAN N., et al.: Role of trunk rehabilitation on trunk control, balance and gait in patients with chronic stroke, a pre post design. Neurosci. Med., 2: 61-7, 2011.

18- KHALILI M. and HAJIHASSANIE A.: Electrical simulation in addition to passive stretch has a small effect on spasticity and contracture in children with cerebral palsy: A randomised within-participant controlled trial. Aust. J. Physiother., 54: 185-9, 2008.

\section{تآثير التنبيه الكهرباتئى لعضلات البطن والظهر على الإتزان

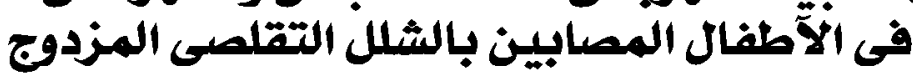

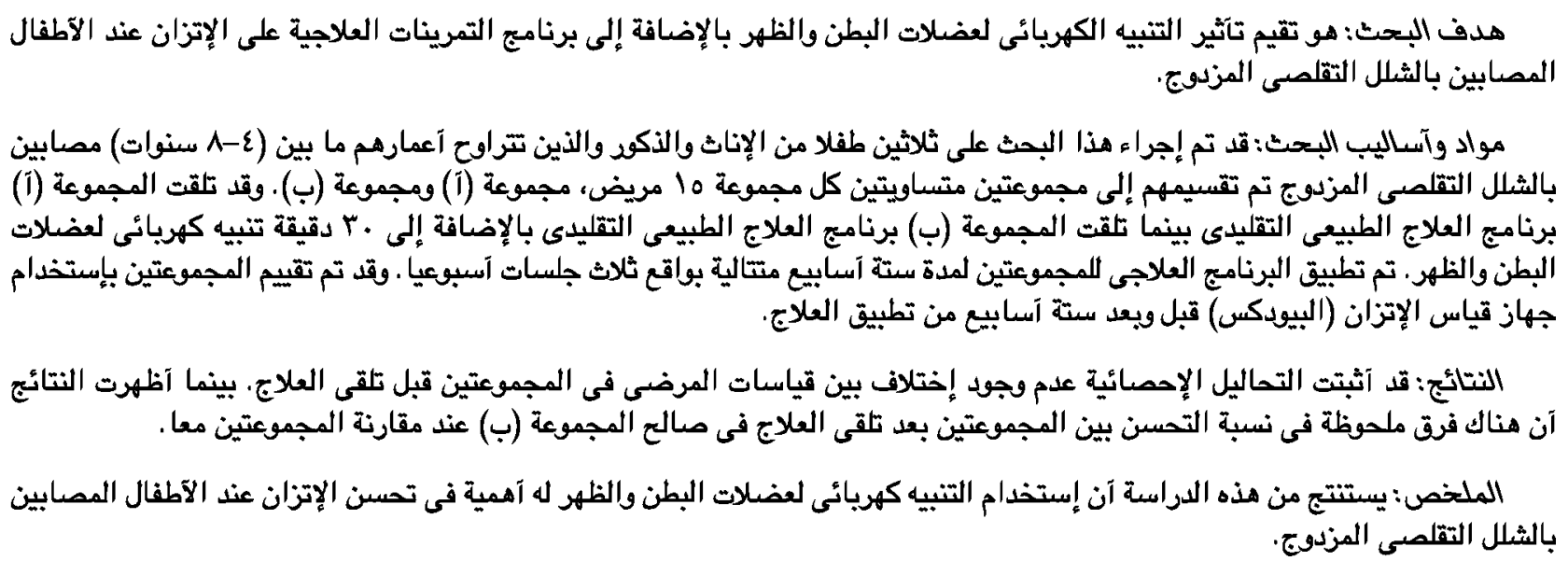

